\title{
Fixed point theory for generalized Ćirić quasi-contraction maps in metric spaces
}

F Kiany ${ }^{1}$ and A Amini-Harandi ${ }^{2,3 *}$

${ }^{\text {"Correspondence: }}$ aminih_a@yahoo.com

${ }^{2}$ Department of Pure Mathematics, University of Shahrekord, Shahrekord, 88186-34141, Iran ${ }^{3}$ School of Mathematics, Institute for Research in Fundamental Sciences (IPM), P.O. Box 19395-5746, Tehran, Iran

Full list of author information is available at the end of the article

\begin{abstract}
In this paper, we first give a new fixed point theorem for generalized Ćirić quasi-contraction maps in generalized metric spaces. Then we derive a common fixed point result for quasi-contractive type maps. Some examples are given to support our results. Our results extend and improve some fixed point and common fixed point theorems in the literature.
\end{abstract}

MSC: $47 \mathrm{H} 10$

Keywords: fixed points; common fixed point; generalized Ćirić quasi-contraction maps

\section{Introduction and preliminaries}

The well-known Banach fixed point theorem asserts that if $(X, d)$ is a complete metric space and $T: X \rightarrow X$ is a map such that

$$
d(T x, T y) \leq c d(x, y) \quad \text { for each } x, y \in X
$$

where $0 \leq c<1$, then $T$ has a unique fixed point $\bar{x} \in X$ and for any $x_{0} \in X$, the sequence $\left\{T^{n} x_{0}\right\}$ converges to $\bar{x}$.

In recent years, a number of generalizations of the above Banach contraction principle have appeared. Of all these, the following generalization of Cirić [1] stands at the top.

Theorem 1.1 Let $(X, d)$ be a complete metric space. Let $T: X \rightarrow X$ be a Cirić quasicontraction map, that is, there exists $c<1$ such that

$$
d(T x, T y) \leq c \max \{d(x, y), d(x, T x), d(y, T y), d(x, T y), d(y, T x)\}
$$

for any $x, y \in X$. Then $T$ has a unique fixed point $\bar{x} \in X$ and for any $x_{0} \in X$, the sequence $\left\{T^{n} x_{0}\right\}$ converges to $\bar{x}$.

For other generalizations of the above theorem, see [2] and the references therein.

\section{Main results}

Let $X$ be a nonempty set and let $d: X \times X \rightarrow[0, \infty]$ be a mapping. If $d$ satisfies all of the usual conditions of a metric except that the value of $d$ may be infinity, we say that $(X, d)$ is a generalized metric space.

(c) 2013 Kiany and Amini-Harandi; licensee Springer. This is an Open Access article distributed under the terms of the Creative Commons Attribution License (http://creativecommons.org/licenses/by/2.0), which permits unrestricted use, distribution, and reproduction in any medium, provided the original work is properly cited. 
We now introduce the concept of a generalized Cirić quasi-contraction map in generalized metric spaces.

Definition 2.1 Let $(X, d)$ be a generalized metric space. The self-map $T: X \rightarrow X$ is said to be a generalized Cirić quasi-contraction if

$$
d(T x, T y) \leq \alpha(d(x, y)) \max \{d(x, y), d(x, T x), d(y, T y), d(x, T y), d(y, T x)\}
$$

for any $x, y \in X$, where $\alpha:[0, \infty] \rightarrow[0,1)$ is a mapping.

As the following simple example due to Sastry and Naidu [3] shows, Theorem 1.1 is not true for generalized Ćirić quasi-contraction maps even if we suppose $\alpha$ is continuous and increasing.

Example 2.2 Let $X=[1, \infty)$ with the usual metric, $T: X \rightarrow X$ be given by $T x=2 x$. Define $\alpha:[0, \infty) \rightarrow[0,1)$ by $\alpha(t)=\frac{2 t}{1+2 t}$. Then, clearly, $\alpha$ is continuous and increasing, and

$$
|T x-T y| \leq \alpha(|x-y|) \max \{|x-y|,|x-T x|,|y-T y|,|x-T y|,|y-T x|\}
$$

for each $x, y \in X$, but $T$ has no fixed point.

Now, a natural question is what further conditions are to be imposed on $T$ or $\alpha$ to guarantee the existence of a fixed point for $T$ ? For some partial answers to this question and application of quasi-contraction maps to variational inequalities, see [4] and the references therein.

Now, we are ready to state our main result.

Theorem 2.3 Let $(X, d)$ be a complete generalized metric space. Let $T: X \rightarrow X$ be a generalized Ćirić quasi-contraction map such that $\alpha$ satisfies

$$
\limsup _{t \rightarrow r} \alpha(t)<1 \quad \text { for each } r \in[0, \infty)
$$

Assume that there exists an $x_{0} \in X$ with the bounded orbit, that is, the sequence $\left\{T^{n} x_{0}\right\}$ is bounded. Furthermore, suppose that $d(x, T x)<\infty$ for each $x \in X$. Then $T$ has a fixed point $\bar{x} \in X$ and $\lim _{n \rightarrow \infty} T^{n} x_{0}=\bar{x}$. Moreover, if $\bar{y}$ is a fixed point of $T$, then either $d(\bar{x}, \bar{y})=\infty$ or $\bar{x}=\bar{y}$.

Proof If for some $n_{0} \in \mathbb{N}, T^{n_{0}-1} x_{0}=T^{n_{0}} x=T\left(T^{n_{0}-1} x_{0}\right)$, then $T^{n} x_{0}=T^{n_{0}-1} x_{0}$ for $n \geq n_{0}$. Thus, $T^{n_{0}-1} x_{0}$ is a fixed point of $T$, the sequence $\left\{T^{n} x_{0}\right\}$ is convergent to $T^{n_{0}-1} x_{0}$, and we are finished (note that $T^{n} x_{0}=T^{n_{0}-1} x_{0}$ for each $n \geq n_{0}$ ). So, we may assume that $T^{n-1} x_{0} \neq$ $T^{n} x_{0}$ for each $n \in \mathbb{N}$. Now, we show that there exists $0<c<1$ such that

$$
\alpha\left(d\left(T^{n-1} x_{0}, T^{n} x_{0}\right)\right)<c \text { for each } n=0,1,2,3, \ldots
$$

On the contrary, assume that

$$
\lim _{k \rightarrow \infty} \alpha\left(d\left(T^{n_{k}-1} x_{0}, T^{n_{k}} x_{0}\right)\right)=1
$$


for some subsequence $\left\{\alpha\left(d\left(T^{n_{k}-1} x_{0}, T^{n_{k}} x_{0}\right)\right)\right\}$ of $\left\{\alpha\left(d\left(T^{n-1} x_{0}, T^{n} x_{0}\right)\right)\right\}$. Since by our assumption the sequence $\left\{d\left(T^{n-1} x_{0}, T^{n} x_{0}\right)\right\}$ is bounded, then the subsequence $\left\{d\left(T^{n_{k}-1} x_{0}\right.\right.$, $\left.\left.T^{n_{k}} x_{0}\right)\right\}$ is bounded too, and so, by passing to subsequences if necessary, we may assume that it is convergent. Let $r_{0}=\lim _{k \rightarrow \infty} d\left(T^{n_{k}-1} x_{0}, T^{n_{k}} x_{0}\right)$. Then from (2.1), we have $\limsup \operatorname{sur}_{t \rightarrow} \alpha(t)=1$, a contradiction. Thus, (2.1) holds.

Now, we show that $\left\{T^{n} x_{0}\right\}$ is a Cauchy sequence. To prove the claim, we first show by induction that for each $n \geq 2$,

$$
d\left(T^{n-1} x_{0}, T^{n} x_{0}\right) \leq K c^{n-1},
$$

where $K$ is a bound for the bounded sequence $\left\{d\left(x_{0}, T^{n} x_{0}\right)\right\}_{n}$. If $n=2$ then, we get

$$
\begin{aligned}
d\left(T x_{0}, T^{2} x_{0}\right) & \leq \alpha\left(d\left(x_{0}, T x_{0}\right)\right) \max \left\{d\left(x_{0}, T x_{0}\right), d\left(T x_{0}, T^{2} x_{0}\right), d\left(x_{0}, T^{2} x_{0}\right)\right\} \\
& =\alpha\left(d\left(x_{0}, T x_{0}\right)\right) \max \left\{d\left(x_{0}, T x_{0}\right), d\left(x_{0}, T^{2} x_{0}\right)\right\} \leq K c .
\end{aligned}
$$

Thus, (2.2) holds for $n=2$. Suppose that (2.2) holds for each $k<n$, and we show that it holds for $k=n$. Since $T$ is a generalized Ćirić quasi-contraction map, then we have

$$
d\left(T^{n-1} x_{0}, T^{n} x_{0}\right) \leq \alpha\left(T^{n-2} x_{0}, T^{n-1} x_{0}\right) u \leq c u,
$$

where

$$
u \in\left\{d\left(T^{n-2} x_{0}, T^{n-1} x_{0}\right), d\left(T^{n-2} x_{0}, T^{n} x_{0}\right)\right\} .
$$

It is trivial that (2.2) holds if $u=d\left(T^{n-2} x_{0}, T^{n-1} x_{0}\right)$. Now, suppose that $u=d\left(T^{n-2} x_{0}, T^{n} x_{0}\right)$. In this case, we have

$$
d\left(T^{n-2} x_{0}, T^{n} x_{0}\right) \leq c u_{1},
$$

where

$$
\begin{aligned}
u_{1} \in & \left\{d\left(T^{n-3} x_{0}, T^{n-1} x_{0}\right), d\left(T^{n-2} x_{0}, T^{n-1} x_{0}\right),\right. \\
& \left.d\left(T^{n-3} x_{0}, T^{n-2} x_{0}\right), d\left(T^{n-3} x_{0}, T^{n} x_{0}\right), d\left(T^{n-1} x_{0}, T^{n} x_{0}\right)\right\} .
\end{aligned}
$$

Again, it is trivial that (2.2) holds if $u_{1}=d\left(T^{n-1} x_{0}, T^{n} x_{0}\right)$ or $u_{1}=d\left(T^{n-3} x_{0}, T^{n-2} x_{0}\right)$. If $u_{1}=$ $d\left(T^{n-2} x_{0}, T^{n-1} x_{0}\right)$, then

$$
d\left(T^{n-1} x_{0}, T^{n} x_{0}\right) \leq c^{2} d\left(T^{n-2} x_{0}, T^{n-1} x_{0}\right) .
$$

By the assumption of induction,

$$
d\left(T^{n-2} x_{0}, T^{n-1} x_{0}\right) \leq K c^{n-2} .
$$

Hence,

$$
d\left(T^{n-1} x_{0}, T^{n} x_{0}\right) \leq K c^{n} \leq K c^{n-1}
$$




$$
\begin{aligned}
& \text { If } u_{1}=d\left(T^{n-3} x_{0}, T^{n-1} x_{0}\right) \text {, then } \\
& \qquad d\left(T^{n-1} x_{0}, T^{n} x_{0}\right) \leq c^{2} d\left(T^{n-3} x_{0}, T^{n-1} x_{0}\right) . \\
& \text { If } u_{1}=d\left(T^{n-3} x_{0}, T^{n} x_{0}\right) \text {, then } \\
& \qquad d\left(T^{n-1} x_{0}, T^{n} x_{0}\right) \leq c^{2} d\left(T^{n-3} x_{0}, T^{n} x_{0}\right) .
\end{aligned}
$$

Therefore, by continuing this process, we see that (2.2) holds for each $n \geq 2$. From (2.2), we deduce that $\left\{T^{n} x_{0}\right\}$ is a Cauchy sequence and since $(X, d)$ is a generalized complete metric space, then there exists an $\bar{x} \in X$ such that $\lim _{n \rightarrow \infty} T^{n} x_{0}=\bar{x}$. Now, we show that $\bar{x}$ is a fixed point of $T$. To show the claim, we first show that there exists $0<k<1$ such that $\alpha\left(d\left(\bar{x}, T^{n} x_{0}\right)\right)<k$ for each $n \in \mathbb{N}$. On the contrary, assume that $\lim _{j \rightarrow \infty} \alpha\left(d\left(\bar{x}, T^{n_{j}} x_{0}\right)\right)=$ 1 for some subsequence $n_{j}$. Since $\lim _{j \rightarrow \infty} d\left(\bar{x}, T^{n_{j}} x_{0}\right)=0$, then from the above, we get $\limsup \operatorname{su}_{t \rightarrow 0^{+}} \alpha(t)=1$, a contradiction. Since $T$ is a generalized Ćirić quasi-contraction, then we have

$$
\begin{aligned}
& d\left(T \bar{x}, T^{n+1} x_{0}\right) \\
& \leq \alpha\left(d\left(\bar{x}, T^{n} x_{0}\right)\right) \max \left\{d\left(\bar{x}, T^{n} x_{0}\right), d(\bar{x}, T \bar{x}),\right. \\
& \left.\quad d\left(T^{n} x_{0}, T^{n+1} x_{0}\right), d\left(\bar{x}, T^{n+1} x_{0}\right), d\left(T^{n} x_{0}, T \bar{x}\right)\right\} \\
& \leq k \max \left\{d\left(\bar{x}, T^{n} x_{0}\right), d(\bar{x}, T \bar{x}), d\left(T^{n} x_{0}, T^{n+1} x_{0}\right), d\left(\bar{x}, T^{n+1} x_{0}\right), d\left(T^{n} x_{0}, T \bar{x}\right)\right\} .
\end{aligned}
$$

Then we have

$$
d(T \bar{x}, \bar{x})=\limsup _{n \rightarrow \infty} d\left(T \bar{x}, T^{n+1} x_{0}\right) \leq k \limsup _{n \rightarrow \infty} d\left(T \bar{x}, T^{n} x_{0}\right)=k d(T \bar{x}, \bar{x}),
$$

which yields $d(T \bar{x}, \bar{x})=0$, and so $\bar{x}=T \bar{x}$ (note that $0<k<1$ and $d(T \bar{x}, \bar{x})<\infty$ by our assumptions). Now, let us assume that $\bar{x}$ and $\bar{y}$ are fixed points of $T$ such that $d(\bar{x}, \bar{y})<\infty$. Then

$$
\begin{aligned}
d(\bar{x}, \bar{y}) & =d(T \bar{x}, T \bar{y}) \\
& \leq \alpha(d(\bar{x}, \bar{y})) \max \{d(\bar{x}, \bar{y}), d(\bar{x}, T \bar{x}), d(\bar{y}, T \bar{y}), d(\bar{x}, T \bar{y}), d(\bar{y}, T \bar{x})\} \\
& =\alpha(d(\bar{x}, \bar{y})) d(\bar{x}, \bar{y}),
\end{aligned}
$$

and so $\bar{x}=\bar{y}($ note that $\alpha(d(\bar{x}, \bar{y}))<1)$.

The following example shows that in the statement of Theorem 2.3, the condition $d(x, T x)<\infty$ for each $x \in X$ is necessary.

Example 2.4 Let $X=\{0, \infty\}, d(0,0)=d(\infty, \infty)=0$ and let $d(0, \infty)=\infty$. Let $T: X \rightarrow X$ be given by $T 0=\infty$ and $T \infty=0$. Then

$$
d(T x, T y) \leq \frac{1}{2} d(x, y) \leq \frac{1}{2} \max \{d(x, y), d(x, T x), d(y, T y), d(x, T y), d(y, T x)\}
$$

for each $x, y \in X$, but $T$ is fixed point free. 
Example 2.5 Let $X=[0, \infty], d(x, y)=|x-y|$ for each $x, y \in[0, \infty), d(x, \infty)=\infty$ for each $x \in[0, \infty)$ and let $d(\infty, \infty)=0$. Then $(X, d)$ is a complete generalized metric space. Let $T: X \rightarrow X$ be given by $T x=2 x$ for each $x \in[0, \infty)$ and $T \infty=\infty$. Define $\alpha:[0, \infty] \rightarrow[0,1)$ by $\alpha(t)=\frac{2 t}{1+2 t}$ for each $t \in[0, \infty)$ and $\alpha(\infty)=\frac{1}{2}$. Then we have

$$
|T x-T y| \leq \alpha(|x-y|) \max \{|x-y|,|x-T x|,|y-T y|,|x-T y|,|y-T x|\},
$$

and $d(x, T x)<\infty$ for each $x, y \in X$. Thus, all of the assumptions of Theorem 2.3 are satisfied, and so $T$ has a unique fixed point $(x=\infty$ is a unique fixed point of $T$ ). But we cannot invoke the above mentioned theorem of Ćirić to show the existence of a fixed point for $T$.

To prove the following common fixed point result, we use the technique in [5].

Corollary 2.6 Let $(X, d)$ be a complete metric space and let the self-maps $T$ and $S$ satisfy the contractive condition

$$
\begin{aligned}
& d(T x, T y) \\
& \quad \leq \alpha(d(S x, S y)) \max \{d(S x, S y), d(S x, T x), d(S y, T y), d(S x, T y), d(S y, T x)\}
\end{aligned}
$$

for each $x, y \in X$, where $\alpha$ satisfies $\lim \sup _{t \rightarrow r^{+}} \alpha(t)<1$ for each $r \in[0, \infty)$. If $T X \subseteq S X$ and $S X$ is a complete subset of $X$, then $T$ and $S$ have a unique coincidence point in $X$. Moreover, if $T$ and $S$ are weakly compatible (i.e., they commute at their coincidence points), then $T$ and $S$ have a unique common fixed point.

Proof It is well known that there exists $E \subseteq X$ such that $S E=S X$ and $S: E \rightarrow X$ is one-toone. Now, define a map $U: S E \rightarrow S E$ by $U(S x)=T x$. Since $S$ is one-to-one on $E, U$ is well defined. Note that

$$
\begin{aligned}
& d(U(S x), U(S y)) \\
& \quad=U(T x, T y) \\
& \quad \leq \alpha(d(S x, S y)) \max \{d(S x, S y), d(S x, T x), d(S y, T y), d(S x, T y), d(S y, T x)\}
\end{aligned}
$$

for all $S x, S y \in S E$. Since $S E=S X$ is complete, by using Theorem 2.3, there exists $\bar{x} \in X$ such that $U(S \bar{x})=S \bar{x}$. Then $T \bar{x}=S \bar{x}$, and so $T$ and $S$ have a coincidence point, which is also unique. Since $T \bar{x}=S \bar{x}$ and $T$ and $S$ commute, then we have

$$
T(T \bar{x})=T^{2} \bar{x}=T S \bar{x}=S T \bar{x}=S^{2} \bar{x}=S(S \bar{x}) .
$$

Thus, $T \bar{x}=S \bar{x}$ is also a coincidence point of $T$ and $S$. By the uniqueness of a coincidence point of $T$ and $S$, we get $T \bar{x}=S \bar{x}=\bar{x}$.

The authors declare that they have no competing interests. 


\section{Author details}

${ }^{1}$ Faculty of Science, Ahvaz Branch, Islamic Azad University, Ahvaz, Iran. ${ }^{2}$ Department of Pure Mathematics, University of Shahrekord, Shahrekord, 88186-34141, Iran. ${ }^{3}$ School of Mathematics, Institute for Research in Fundamental Sciences (IPM), P.O. Box 19395-5746, Tehran, Iran.

\section{Acknowledgements}

The authors are grateful to the referees for their helpful comments leading to improvement of the presentation of the work. The second author acknowledge that this research was partially carried out at IPM-Isfahan Branch. The second author was partially supported by a grant from IPM (No. 91470412) and by the Center of Excellence for Mathematics, University of Shahrekord, Iran.

Received: 16 June 2012 Accepted: 13 January 2013 Published: 6 February 2013

\section{References}

1. Ćirić, LB: A generalization of Banach's contraction principle. Proc. Am. Math. Soc. 45(2), 267-273 (1974)

2. Amini-Harandi, A: Fixed point theory for set-valued quasi-contraction maps in metric spaces. Appl. Math. Lett. 24 1791-1794 (2011)

3. Sastry, KPR, Naidu, SVR: Fixed point theorems for generalized contraction mappings. Yokohama Math. J. 28, 15-19 (1980)

4. Ćirić, L, Hussain, N, Cakić, N: Common fixed points for Ćirić type $f$-weak contraction with applications. Publ. Math. (Debr.) 76, 31-49 (2010)

5. Haghi, RH, Rezapour, S, Shahzad, N: Some fixed point generalizations are not real generalizations. Nonlinear Anal. 74, 1799-1803 (2011)

doi:10.1186/1687-1812-2013-26

Cite this article as: Kiany and Amini-Harandi: Fixed point theory for generalized Ćirić quasi-contraction maps in metric spaces. Fixed Point Theory and Applications 2013 2013:26.

\section{Submit your manuscript to a SpringerOpen ${ }^{\circ}$ journal and benefit from:}

- Convenient online submission

- Rigorous peer review

- Immediate publication on acceptance

Open access: articles freely available online

High visibility within the field

- Retaining the copyright to your article 